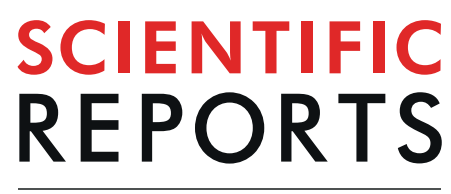

natureresearch

Check for updates

\title{
Independent Predictors of Mortality for Aeromonas Necrotizing Fasciitis of Limbs: An 18-year Retrospective Study
}

Tsung-Yu Huang ${ }^{1,2,3}$, Kuo-Ti Peng ${ }^{2,4,5}$, Wei-Hsiu Hsu ${ }^{2,4,5}$, Chien-Hui Hung ${ }^{1,2}$, Fang-Yi Chuang ${ }^{6}$.
Yao-Hung Tsai ${ }^{2,4,5}$ (a)

Necrotizing fasciitis (NF) of the limbs caused by Aeromonas species is an extremely rare and lifethreatening skin and soft tissue infection. The purpose of this study was to evaluate the specific characteristics and the independent predictors of mortality in patients with Aeromonas NF. Sixty-eight patients were retrospectively reviewed over an 18-year period. Differences in mortality, demographics data, comorbidities, symptoms and signs, laboratory findings, microbiological analysis, empiric antibiotics treatment and clinical outcomes were compared between the non-survival and the survival groups. Twenty patients died with the mortality rate of $29.4 \%$. The non-survival group revealed significant differences in bacteremia, monomicrobial infection, cephalosporins resistance, initial ineffective empiric antibiotics usage, chronic kidney disease, chronic hepatic dysfunction, tachypnea, shock, hemorrhagic bullae, skin necrosis, leukopenia, band polymorphonuclear neutrophils $>10 \%$, anemia, and thrombocytopenia. The multivariate analysis identified four variables predicting mortality: bloodstream infection, shock, skin necrosis, and initial ineffective empirical antimicrobial usage against Aeromonas. NF caused by Aeromonas spp. revealed high mortality rates, even through aggressive surgical debridement and antibacterial therapies. Identifying those independent predictors, such as bacteremia, shock, progressive skin necrosis, monomicrobial infection, and application of the effective antimicrobial agents against Aeromonas under the supervision of infectious doctors, may improve clinical outcomes.

Necrotizing fasciitis (NF) is a rare and life-threatening necrotizing soft tissue infection (NSSTI) characterized by a rapid bacterial spread with soft tissue necrosis in the subcutaneous layers, particularly within superficial and deep fascia, with overall mortality rates of $12.1-76 \%{ }^{1-8}$. Early fasciotomy, an appropriate empiric antimicrobial therapy supported by physicians specialized in infectious disease, and aggressive intensive unit care should be initially administered in critically ill patients suffering from fulminant NF to prevent limb loss and possible death ${ }^{9-11}$.

Our hospital is situated on the western coast of southern Taiwan, and most residents are exposed to occupations related to seawater, raw seafood, fresh or brackish water, and soil. As a result, Vibrio spp. and Aeromonas spp. infections have been reported at a relatively high incidence since 2004 in our hospital ${ }^{9,12-19}$. Thus, we set up the team "Vibrio NSSTIs Treatment and Research (VTR) Group", which consists of professional staff working in various departments, including emergency medicine, orthopedic surgery, infectious diseases, intensive care unit (ICU), and hyperbaric oxygen treatment center. Our team has successfully decreased the mortality rate of Vibrio NF from $35 \%$ to $13 \%^{8,12}$.

Although we have established a treatment strategy including emergency fasciotomy or amputation, antibiotic therapy with a third-generation cephalosporin plus tetracycline, and admission to the ICU for patients suspected

\footnotetext{
${ }^{1}$ Division of Infectious Diseases, Department of Internal Medicine, Chang Gung Memorial Hospital, Chiayi, Taiwan. ${ }^{2}$ Graduate Institute of Clinical Medical Sciences, College of Medicine, Chang Gung University, Taoyuan, Taiwan. ${ }^{3}$ Department of Nursing, Chang Gung University of Science and Technology, Chiayi Campus, Chiayi, Taiwan. ${ }^{4}$ Department of Orthopedic Surgery, Chang Gung Memorial Hospital, Chiayi, Taiwan. ${ }^{5}$ Department of Chinese Medicine, School of Medicine, Chang Gung University, Chiayi, Taiwan. ${ }^{6}$ Department of Laboratory Medicine, Chang Gung Memorial Hospital, Chiayi, Taiwan. ${ }^{\circledR}$ e-mail: orma2244@adm.cgmh.org.tw
} 


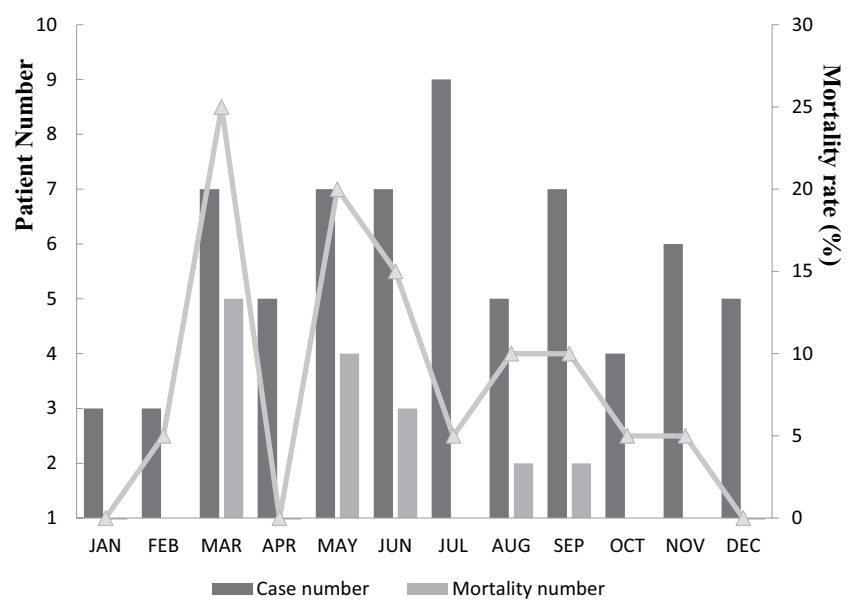

Figure 1. Monthly distribution of 68 cases of Aeromonas spp. necrotizing fasciitis of limbs in southern Taiwan.

to have fulminant necrotizing fasciitis, such as Vibrio, MRSA, and Aeromonas infections $8,9,14,17,19$. Aeromonas species NSSTIs were still reported with a high mortality rate ranging from $26.7 \%$ to $100 \%{ }^{7-10,13,14,20-23}$.

Aeromonas species are members of the Vibrionaceae and are gram-negative, non-sporulating, facultative, anaerobic small bacilli with a ubiquitous distribution ${ }^{24,25}$. Human infections including acute gastroenteritis, blood-borne infections, trauma-related skin and soft tissue infections (SSTIs), and intra-abdominal infections may develop in previously healthy subjects following aqueous environmental exposure ${ }^{24-28}$. Currently, there are more than 20 Aeromonas species identified, but only seven have been recognized as human pathogens, namely, A. hydrophila, A. caviae, A. veronii biovar sobria, A. veronii biovar veronii, $A$. jandaei, $A$. trota, and $A$. schubertii, with the first three being the most common causes of $\mathrm{NF}^{24,29}$ The aim of this study was to evaluate the specific characteristics and the independent predictors of mortality in patients with Aeromonas NF, and to gain insight and improve future outcomes.

\section{Results}

Patients outcomes. From December 2001 to November 2019, a total 68 of patients admitted to the ED were surgically confirmed to have Aeromonas NF of limbs. Forty-eight patients survived, and 20 expired with a mortality rate of $29.4 \%$. The numbers of diagnoses, cases of death, and mortality rates are listed per month (Fig. 1).

Demographic data. No significant differences were observed within the parameters of age, gender, infective regions, or the number of amputations per patient between these two groups. The non-survival group was characterized by a significantly higher incidence of chronic kidney disease (CKD), chronic liver dysfunction, and ICU admission (Table 1). Meanwhile, the non-survival group had significantly associated with higher Acute Physiology and Chronic Health Evaluation II (APACHE ${ }^{\mathrm{a}}$ II) scores, fewer operations, and shorter hospitalization stays (Table 1).

Microbiological analysis. Aeromonas hydrophila was the most common infectious bacteria, accounting for $46(67.6 \%)$ of the total 68 Aeromonas NF cases, followed by 10 Aeromonas sobria cases (14.7\%), 9 Aeromonas cases (13.2\%), and 3 of Aeromonas caviae (4.4\%). A total of 42 (61.8\%) of these patients were diagnosed with polymicrobial Aeromonas NFs of limbs. The most common isolates obtained from patients with polymicrobial infections included Clostridium species (21,50.0\%), followed by Enterobacter species (14, 33.3\%) and Klebsiella species $(11,26.2 \%)$ (Table 2$)$. The non-survival group had a higher incidence of bacteremia (70\% vs. $25 \%$; $p=0.001)$ than the survival group, and were significantly associated with monomicrobial infection $(p=0.018)$. Meanwhile, the survival group had a higher incidence of polymicrobial infection and coinfection with anaerobic pathogens ( $p=0.017$ and $p=0.016$, respectively) than the non-survival group. Concerning antibiotic resistance to Aeromonas species, only resistant to cephalosporins exhibited a statistically significant increase ( $40 \%$ vs. $14.6 \% ; p=0.021)$ within the non-survival group. In terms of initial ineffective empirical antimicrobial usage, the non-survival group had a higher incidence ( $45 \%$ vs. $18.8 \%$; $p=0.025$ ) than the survival group (Table 3 ).

Clinical presentations. No significant differences in the presentation of fever $\left(>38^{\circ} \mathrm{C}\right)$; tachycardia (heartbeat $>100 / \mathrm{min}$ ); or erythematous, swollen, and painful lesion were observed between the two groups (Table 4). However, the proportion of patients in the non-survival versus survival group presenting with tachypnea (respiratory rate $>20 / \mathrm{min}, 70.0 \%$ vs. $37.5 \%$; $p=0.014$ ), shock (systolic blood pressure $<90 \mathrm{mmHg}, 80.0 \%$ vs. $29.2 \%$; $p<0.001)$, hemorrhagic bullae ( $60.0 \%$ vs. $29.2 \%, p=0.017)$, and skin necrosis $(55.0 \%$ vs. $16.7 \%, p=0.001)$ were higher (Table 4).

Laboratory findings. Within the non-survival group the following characteristics were observed more frequently than within the survival group: total white blood cell count $<4000 / \mathrm{uL}$, band leukocyte cells $>10 \%$, lymphocyte count of leukocytes $<1000 / \mathrm{uL}$, anemia (hemoglobin $<10 \mathrm{~g} / \mathrm{dL}$ ), thrombocytopenia (platelet count $<15$ $\times 10^{4} / \mathrm{uL}$ ), and estimated glomerular filtration rate $<30$ c.c./min (Table 5). In addition, the proportion of patients presenting with a lower albumin level was frequently observed and significantly higher in the non-survival group 


\begin{tabular}{|c|c|c|c|}
\hline Variable & $\begin{array}{l}\text { Survival } \\
(\mathrm{n}=48)\end{array}$ & $\begin{array}{l}\text { Non-survival } \\
(\mathbf{n}=20)\end{array}$ & $p$-value \\
\hline Age (years) & $60.52 \pm 15.44$ & $64.85 \pm 12.89$ & 0.274 \\
\hline Gender, male & $40(83.3)$ & $14(70)$ & 0.215 \\
\hline \multicolumn{4}{|l|}{ Involved region } \\
\hline Upper extremities & $12(25)$ & $1(5)$ & 0.056 \\
\hline Lower extremities & $36(75)$ & $19(95)$ & 0.056 \\
\hline APACHE ${ }^{a}$ II score & $12.48 \pm 6.65$ & $23.9 \pm 7.33$ & $<0.001^{*}$ \\
\hline \multicolumn{4}{|l|}{ Underlying chronic diseases } \\
\hline Alcoholism & $10(20.8)$ & $7(35)$ & 0.219 \\
\hline Chronic kidney disease & $12(25)$ & $15(75)$ & $<0.001^{*}$ \\
\hline Cardiovascular disease & $9(18.8)$ & $5(25)$ & 0.561 \\
\hline Cerebrovascular accident & $5(10.4)$ & $2(10)$ & 0.959 \\
\hline Viral hepatitis & $17(35.4)$ & $12(60)$ & 0.062 \\
\hline Liver cirrhosis & $13(27.1)$ & $9(45)$ & 0.150 \\
\hline Chronic liver dysfunction & $23(47.9)$ & $16(80)$ & $0.015^{*}$ \\
\hline Diabetes Mellitus & $24(50)$ & $14(70)$ & 0.130 \\
\hline Malignancy & $14(29.2)$ & $5(25)$ & 0.727 \\
\hline Peripheral vascular disease & $7(14.6)$ & $4(20)$ & 0.580 \\
\hline Patients number of amputations & $12(25)$ & $8(40)$ & 0.216 \\
\hline $\mathrm{ICU}^{\mathrm{b}}$ admission & $23(47.9)$ & $19(95)$ & $<0.001^{*}$ \\
\hline $\mathrm{TiSO}^{\mathrm{c}}>24 \mathrm{~h}$ & $15(31.3)$ & $6(30)$ & 0.919 \\
\hline Number of debridement & $3.5 \pm 2.1$ & $1.6 \pm 1.0$ & $<0.001^{*}$ \\
\hline ICU stay (day) & $6.4 \pm 14.7$ & $13.5 \pm 21.1$ & 0.117 \\
\hline Hospital stay (day) & $37.9 \pm 20.2$ & $17.1 \pm 36.8$ & $0.004 *$ \\
\hline
\end{tabular}

Table 1. Demographic data and characteristics from Aeromonas NF between survival and non-survival groups. Data were presented as mean (standard deviation) or frequency $(\%) .{ }^{*} p$-value $<0.05 .{ }^{a} \mathrm{APACHE}$ : Acute Physiology and Chronic Health Evaluation, ${ }^{\mathrm{b}} \mathrm{ICU}$ : intensive care unit, ${ }^{\mathrm{c}} \mathrm{TiSO}$ : time of the first surgical intervention from symptom onset to the operating room.

$(p=0.002)$. The prothrombin time (PT) and total bilirubin values for the non-survival group were significantly higher than those for the survival group (Table 5).

Multivariate analysis. As determined by multivariate analysis, patients presented with bloodstream infection (OR: 8.741; 95\% CI: 1.936-39.476; $p=0.005$ ), shock(OR: 5.926; 95\% CI: $1.254-28.006 ; p=0.025$ ), skin necrosis (OR: 4.575 ; 95\% CI: $1.190-17.597 ; p=0.027$ ), and a higher incidence of initial ineffective empirical antimicrobial usage (OR: 5.798; 95\% CI: 1.247-26.951; $p=0.025$ ) were the indicators of mortality (Table 6).

\section{Discussion}

Most Aeromonas SSTIs are associated with environmental exposure and are particularly related to traumatic occupational injuries or unexpected contact via recreational sporting activities ${ }^{27,28}$. This mode of acquisition results in soft tissue Aeromonas infections occurring more commonly during the summer season ${ }^{25}$. Our study was consistent with this finding.

Aeromonas SSTIs are often polymicrobial and frequently involve coinfections with other gram-negative rods or Clostridium species ${ }^{25,27,30}$. In studies of Aeromonas SSTIs or bacteremia, A. hydrophila was the most common pathogen isolated, and encompassed $47 \sim 69 \%$ Aeromonas infections ${ }^{26,27,29}$. In our results, $A$. hydrophila was also the most common infectious organism detected (67.6\%), and Clostridium species were the most common coinfection pathogens.

According to past reports, Aeromonas and Clostridial necrotizing soft tissue infections were consistently associated with poor outcomes ${ }^{7,19,31}$. However, our patients exhibiting monomicrobial Aeromonas NF had a significantly higher mortality rate than those with polymicrobial Aeromonas NF. Another interesting phenomenon is that Aeromonas NF patients coinfected with Clostridial species also had better outcomes. On the other hand, we found Aeromonas NF combined with bloodstream infection (BSI) had significantly increased the mortality rate. Monomicrobial Aeromonas NF with bacteremia has commonly been reported to be associated with liver cirrhosis and malignancy that can rapidly impair the phagocytic activity of the reticuloendothelial system and result in septic shock and multiple organ failure ${ }^{14,27,32}$. Thus, we should pay more attention and aggressive treat those NF patients with Aeromonas bacteremia and monomicrobial infection.

Most Aeromonas strains are resistant to ampicillin, amoxicillin, and amoxicillin-clavulanate, whereas most are susceptible to sulfa drugs, fluoroquinolones, second- to fourth-generation cephalosporins, aminoglycosides, carbapenems, and tetracyclines ${ }^{26,28,33,34}$. Therefore, Aeromonas SSTIs may best be treated empirically with fluoroquinolones and/or a third- or fourth-generation cephalosporin or a carbapenem; however, a higher cephalosporins-resistance rate was found in the non-survival group (Table 3). Culture-directed antimicrobial 


\begin{tabular}{|c|c|}
\hline Identified infectious microorganisms & Total No. (\%) \\
\hline \multicolumn{2}{|l|}{ Gram-negative aerobic pathogens } \\
\hline Enterobacter spp. & $14(33.3)$ \\
\hline Enterobacter cloacae & $13(31.0)$ \\
\hline Enterobacter aerogenes & $1(2.4)$ \\
\hline Klebsiella spp. & $11(26.2)$ \\
\hline Klebsiella pneumoniae & $7(16.7)$ \\
\hline Klebsiella oxytoca & $4(9.5)$ \\
\hline Pseudomonas aeruginosa & $10(23.8)$ \\
\hline Escherichia coli & $9(21.4)$ \\
\hline Proteus vulgaris & $4(9.5)$ \\
\hline Citrobacter freundii & $3(7.1)$ \\
\hline Serratia marcescens & $2(4.8)$ \\
\hline Vibrio vulnificus & $1(2.4)$ \\
\hline Morganella morganii & $1(2.4)$ \\
\hline Acinetobacter baumannii & $1(2.4)$ \\
\hline \multicolumn{2}{|l|}{ Gram-positive aerobic pathogens } \\
\hline Enterococcus spp. & $9(21.4)$ \\
\hline Enterococcus faecalis & $8(19.0)$ \\
\hline Enterococcus casseliflavus & $1(2.4)$ \\
\hline Staphylococcus spp. & $4(9.5)$ \\
\hline MRSA $^{\mathrm{a}}$ & $2(4.8)$ \\
\hline MSSA $^{\mathrm{b}}$ & $2(4.8)$ \\
\hline Group D Streptococcus & $1(2.4)$ \\
\hline \multicolumn{2}{|l|}{ Anaerobic pathogens } \\
\hline Clostridium spp. & $21(50.0)$ \\
\hline Clostridium bifermentans & $9(21.4)$ \\
\hline Clostridium sp & $6(14.3)$ \\
\hline Clostridium perfringens & $3(7.1)$ \\
\hline Clostridium bifermentans & $1(2.4)$ \\
\hline Clostridium butyricum & $1(2.4)$ \\
\hline Clostridium novyi $A$ & $1(2.4)$ \\
\hline Peptostreptococcus spp. & $7(16.7)$ \\
\hline Peptostreptococcus anaerobius & $4(9.5)$ \\
\hline Peptostreptococcus sp & $2(4.8)$ \\
\hline Peptostreptococcus magnus & $1(2.4)$ \\
\hline Bacteroides fragilis & $3(7.1)$ \\
\hline Prevotella sp & $3(7.1)$ \\
\hline Total & $42(100)$ \\
\hline
\end{tabular}

Table 2. Summary of identified infectious microorganisms in 42 cases of Aeromonas polymicrobial NF of limbs. Abbreviations: ${ }^{\mathrm{a}}$ MRSA: methicillin-resistant Staphylococcus aureus. ${ }^{\mathrm{b}} \mathrm{MSSA}$ : methicillin-sensitive Staphylococcus aureus.

therapy should be aggressively administered in such Aeromonas NF patients to avoid delayed use of appropriate antimicrobial therapy ${ }^{11,13}$.

A significantly higher mortality rate was observed in NF patients that also exhibited CKD, hepatic dysfunction, diabetes mellitus, and cancer ${ }^{3,6,7,10,19,20,26}$. Our Aeromonas NF patients with CKD or chronic hepatic dysfunction were present in statistically significantly higher numbers in the non-survival compared with the survival group. The non-survival group exhibited high severity of disease and $95 \%$ of patients required admission to the ICU. A delay in the first surgical intervention from symptom onset to the operating room of $>24 \mathrm{~h}$, as well as having advanced age, adversely affected survival outcome $e^{3,20,26}$. A delay in surgery of more than $24 \mathrm{~h}$ accounted for $30 \%$ of the patients within the non-survival group, and the mean age was $>60$ years old within these two groups.

In our study, the non-survival group contained a greater proportion of patients with hemorrhagic bullous lesions ( $60 \%$ vs. $29.2 \%$ ) and skin necrosis (55\% vs. $16.7 \%$ ) than the surviving group, but multivariate logistic regression analysis revealed that non-survival patients presented associated with skin necrosis $(p=0.027)$. As the ischemic necrosis of the skin evolves, gangrene of the subcutaneous fat, dermis, and epidermis, manifesting progressively as bullae formation, ulceration and skin necrosis ${ }^{14,35}$. Hemorrhagic bullae and skin necrosis were also the late stage signals of necrotizing fasciitis $3,35,36$. Then, hemorrhagic bullae with skin necrosis appearance may increase the incidence of mortality (Fig. 2). Nonetheless, the emergence of hemorrhagic bullae would be considered a feature and an early independent predictor of mortality of Aeromonas NF. 


\begin{tabular}{|l|l|l|l|}
\hline Variable & $\begin{array}{l}\text { Survival } \\
(\mathbf{n = 4 8})\end{array}$ & $\begin{array}{l}\text { Non-survival } \\
(\mathbf{n = 2 0})\end{array}$ & $\boldsymbol{p}$-value \\
\hline Bloodstream infection & $12(25)$ & $14(70)$ & $0.001^{*}$ \\
\hline Bacteria isolated & & & $0.018^{*}$ \\
\hline Polymicrobial infection & $34(70.8)$ & $8(40)$ & \\
\hline Monomicrobial infection & $14(29.2)$ & $12(60)$ & \\
\hline Coinfection with anaerobic pathogens & $22(45.8)$ & $3(15)$ & $0.016^{*}$ \\
\hline Coinfection with Clostridial spp. & $17(35.4)$ & $2(10)$ & $0.033^{*}$ \\
\hline Antibiotics that Aeromonas spp. resistant & & & \\
\hline Penicillins & $19(39.6)$ & $5(25)$ & 0.252 \\
\hline Carbapenems & $16(33.3)$ & $7(35)$ & 0.895 \\
\hline Cephalosporins & $7(14.6)$ & $8(40)$ & $0.021^{*}$ \\
\hline Aminoglycosides & $6(12.5)$ & $5(25)$ & 0.202 \\
\hline Sulfa drugs & $4(8.3)$ & $5(25)$ & 0.065 \\
\hline Tetracycline & $3(6.3)$ & $4(20)$ & 0.089 \\
\hline Fluoroquinolones & $1(2.1)$ & $1(5)$ & 0.517 \\
\hline Other class antibiotics & $36(75)$ & $17(85)$ & 0.365 \\
\hline Initial ineffective empirical antimicrobial usage & $9(18.8)$ & $9(45)$ & $0.025^{*}$ \\
\hline
\end{tabular}

Table 3. Microbiological results for Aeromonas species NF between survival and non-survival groups.

\begin{tabular}{|c|c|c|c|c|}
\hline \multirow{2}{*}{\begin{tabular}{|l} 
Variable \\
Systemic symptoms/signs
\end{tabular}} & \multirow[t]{2}{*}{$\begin{array}{l}\text { Survival } \\
(\mathrm{n}=48)\end{array}$} & \multicolumn{2}{|c|}{$\begin{array}{l}\text { Non-survival } \\
(\mathbf{n}=20)\end{array}$} & \multirow[t]{2}{*}{$p$-value } \\
\hline & & & & \\
\hline Fever $\left(>38^{\circ} \mathrm{C}\right)$ & $15(31.3)$ & $5(25)$ & 0.60 & \\
\hline Tachycardia $^{\mathrm{a}}$ & $27(56.3)$ & $15(75)$ & 0.14 & \\
\hline Tachypnea $^{\mathrm{b}}$ & $18(37.5)$ & $14(70)$ & 0.01 & $14 *$ \\
\hline Shock $^{\mathrm{c}}$ & $14(29.2)$ & $16(80)$ & $<0$. & $.001 *$ \\
\hline \multicolumn{5}{|l|}{ Limbs symptoms/signs } \\
\hline Pain and tenderness & $47(97.9)$ & $20(100)$ & 0.51 & \\
\hline Swelling and erythema & $45(93.8)$ & $20(100)$ & 0.25 & \\
\hline Hemorrhagic bullae & $14(29.2)$ & $12(60)$ & 0.01 & $17 *$ \\
\hline Skin necrosis & $8(16.7)$ & $11(55)$ & 0.00 & $01 *$ \\
\hline
\end{tabular}

Table 4. Comparison of clinical presentations between survival and non-survival groups. Data were presented as mean (standard deviation) or frequency (\%). ${ }^{\mathrm{a}}$ Tachycardia: heart beat $>100 / \mathrm{min},{ }^{\mathrm{b}}$ Tachypnea: respiratory rate $>20 / \mathrm{min}$, ${ }^{\mathrm{c}}$ Shock: systolic blood pressure $<90 \mathrm{mmHg}$.

In this study, the non-survival group exhibits a statistical tendency to have tachypnea and initially present with septic shock more than those within the survival group in univariate logistic analysis; however, multivariate logistic regression analysis bacteremia and shock revealed significant differences. Some literatures reported that initial presentations of tachypnea and hypotensive shock were also predictors for a poor outcome in NF patients ${ }^{7,8,10,19}$. This may explain to the fact that the death group presented more septicemia-related systemic inflammatory response symptoms to induce respiratory failure and shock.

Leucopenia, increased counts of banded leukocytes, thrombocytopenia, and severe hypoalbuminemia can be considered the clinical and laboratory risk indicators to initialize surgical intervention and to predict mortality for $\mathrm{NF}^{3-8,15,20,21}$. The non-survival group was associated with a higher rate of patients exhibiting leucopenia, leukocyte band cells $>10 \%$, lymphocytopenia, anemia, and thrombocytopenia compared with the survival group (Table 5). Lower serum albumin levels, prolonged PT, and higher total bilirubin levels were also noted within the non-survival group. These laboratory findings within Aeromonas NF infections are compatible with the aforementioned previous studies.

Multivariate logistic regression analysis revealed the initial ineffective empirical antimicrobial usage are related to poor outcomes for Aeromonas NF patients. Early prompt fasciotomy combined with appropriate antimicrobial therapy has been aggressively performed for patients highly suspected of having NF in our institution $^{8,13,14,17,19}$. In our experience within the ICU, antimicrobial stewardship program and on-the-spot education by physicians specialized in infectious disease can potentially decrease sepsis-related and overall infection-related mortality rates by $54 \%$ and $41 \%$, respectively ${ }^{11}$. The initial clinical presentation of Aeromonas NF is very similar to Vibrio NF, and especially within southern Taiwan, there may be a history of contact with dirty water or fish exposure. To treat these fulminate diseases, third- to fourth-generation cephalosporins combined with tetracycline or fluoroquinolones were commonly the empiric prescription before the infectious pathogens were identified ${ }^{5,37}$. In the non-survival group, we found $40 \%$ of Aeromonas species resistant to cephalosporins and $20 \%$ to tetracycline 


\begin{tabular}{|c|c|c|c|}
\hline Variable & $\begin{array}{l}\text { Survival } \\
(\mathrm{n}=48)\end{array}$ & $\begin{array}{l}\text { Non-survival } \\
(\mathbf{n}=20)\end{array}$ & $p$-value \\
\hline \multicolumn{4}{|l|}{ Total WBC count } \\
\hline Leukocytosis ( $\geqq 12000 / \mathrm{uL})$ & $28(58.3)$ & $6(30)$ & $0.033^{*}$ \\
\hline Leukopenia $(\leqq 4000 / \mathrm{uL})$ & $2(4.2)$ & $6(30)$ & $0.003^{*}$ \\
\hline Leukocytosis or Leukopenia & $30(62.5)$ & $12(60)$ & 0.847 \\
\hline \multicolumn{4}{|l|}{ Differential count } \\
\hline Neutrophilia (>7500/uL) & $38(79.2)$ & $9(45)$ & $0.005^{*}$ \\
\hline Band forms (>10\%) & $7(14.6)$ & $8(40)$ & $0.021^{*}$ \\
\hline Lymphocytopenia (<1000/uL) & $21(43.8)$ & $15(75)$ & $0.019^{*}$ \\
\hline Anemia $\left(\mathrm{Hb}^{\mathrm{b}}<10 \mathrm{~g} / \mathrm{dL}\right)$ & $11(22.9)$ & $12(60)$ & $0.003^{*}$ \\
\hline $\begin{array}{l}\text { Thrombocytopenia (platelet counts }<15 \times \\
10^{4} / \mathrm{uL} \text { ) }\end{array}$ & $20(41.7)$ & $16(80)$ & $0.004^{*}$ \\
\hline $\mathrm{eGFR}^{\mathrm{c}}<30$ c.c. $/ \mathrm{min}$ & $9(18.8)$ & $14(70)$ & $<0.001 *$ \\
\hline Glucose (mg/dL) & $191.0 \pm 116.6$ & $190.3 \pm 116.2$ & 0.983 \\
\hline Sodium (meq/L) & $137.4 \pm 4.4$ & $135.1 \pm 5.9$ & 0.077 \\
\hline C-reactive protein $(\mathrm{mg} / \mathrm{dL})$ & $111.9 \pm 103.8$ & $146.0 \pm 163.6$ & 0.336 \\
\hline $\operatorname{Albumin}(\mathrm{mg} / \mathrm{dL})$ & $2.8 \pm 0.9$ & $2.0 \pm 0.6$ & $0.002 *$ \\
\hline $\mathrm{PT}^{\mathrm{d}}(\mathrm{s})$ & $13.1 \pm 3.3$ & $19.5 \pm 7.5$ & $<0.001^{*}$ \\
\hline Total bilirubin (mg/dL) & $2.1 \pm 2.0$ & $6.2 \pm 5.4$ & $<0.001^{*}$ \\
\hline
\end{tabular}

Table 5. Laboratory findings of patients with Aeromonas NF between survival and non-survival groups. Data were presented as mean (standard deviation) or frequency (\%). Abbreviations: ${ }^{a} \mathrm{WBC}$ : white blood cell; ${ }^{\mathrm{b}} \mathrm{Hb}$ : hemoglobin; ${ }^{c}$ GFR: estimated glomerular filtration rate; ${ }^{\mathrm{d} T}$ : prothrombin time.

\begin{tabular}{|l|l|l|}
\hline & $\mathbf{O R}^{\mathbf{a}}\left(\mathbf{9 5} \% \mathbf{C I}^{\mathrm{b}}\right)$ & $\boldsymbol{p}_{\text {-value }}$ \\
\hline Microbiological results & & \\
\hline Bloodstream infection & $8.741(1.936-39.476)$ & $0.005^{*}$ \\
\hline Aeromonas spp. polymicrobial infection & $0.610(0.136-2.726)$ & 0.517 \\
\hline Coinfection with anaerobic pathogens & $0.518(0.039-6.958)$ & 0.620 \\
\hline Coinfection with Clostridial spp. & $1.151(0.061-21.699)$ & 0.925 \\
\hline Aeromonas spp. resistant to cephalosporins & $2.679(0.635-11.296)$ & 0.180 \\
\hline Initial ineffective empirical antimicrobial usage & $5.798(1.247-26.951)$ & $0.025^{*}$ \\
\hline Systemic symptoms/signs & & \\
\hline Tachypnea & $1.635(0.374-7.155)$ & 0.514 \\
\hline Shock & $5.926(1.254-28.006)$ & $0.025^{*}$ \\
\hline Limbs symptoms/signs & & \\
\hline Hemorrhagic bullae & $1.578(0.414-6.011)$ & 0.504 \\
\hline Skin necrosis & $4.575(1.190-17.597)$ & $0.027^{*}$ \\
\hline
\end{tabular}

Table 6. Multivariate regression for the non-survival group from 68 cases of Aeromonas NF patients about microbiological results and clinical presentations. Abbreviations: ${ }^{\mathrm{a}} \mathrm{OR}$, odds ratio; ${ }^{\mathrm{b}} \mathrm{CI}$, confidence interval.

but only to $5 \%$ fluoroquinolones. So, we consider prescribing third- to fourth-generation cephalosporins combined with tetracycline and fluoroquinolones for highly suspected fulminate Vibrio or Aeromonas NF of limbs within the setting of our hospital. After the pathogens were identified, the antibiotic regimens were adjusted as necessary according to the patient's clinical condition and results of the antibiotics drug sensitivity tests.

The present study was limited by having only 68 patients in a period of 18 years. However, to our knowledge, these are the largest patient numbers within such a study that can be currently found within PubMed. Another limitation contained within is that due to the long study period, some cases, medical records, and laboratory data had been lost and were not able to be recovered.

In conclusion, Aeromonas spp. NF of limbs is very rare and exhibits resistance to multiple antibiotics. NF caused by Aeromonas spp. revealed high mortality rates, even through aggressive surgical debridement and antibacterial therapies. Identifying those independent predictors, such as bacteremia, shock, progressive skin necrosis, monomicrobial infection, and application of the effective antimicrobial agents against Aeromonas under the supervision of infectious doctors, may improve clinical outcomes.

\section{Materials and Methods}

Study design and setting. This is a retrospective study performed by the VTR Group at CGMH-Chiayi from December 2001 to November 2019. We analyzed those patients admitted to the emergency department (ED) that were diagnosed with NF of limbs with undergoing surgical intervention, and a total 68 of patients were surgically and pathologically confirmed to have Aeromonas NF of limbs were included. 


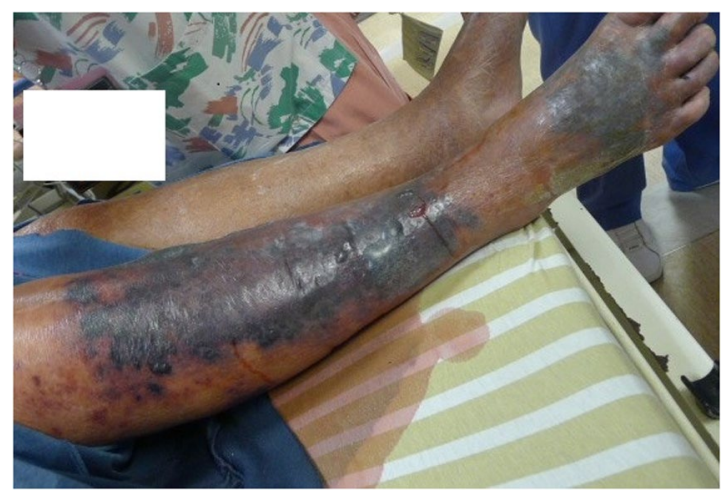

Figure 2. A 82 year-old male with a history of hepatitis B and old stroke had right low leg and foot pain on second day after a contused injury of toes. The right lower leg revealed patchy purpura, vesicles and skin necrosi with serous fluid soaking on the bed in the emergency room. After fasciotomy, the culture of blood and wound specimens confirmed Aeromonas hydrophila, however, this patient died on the 3rd day after admission owing to progressive septic shock and multiple organ failure.

\section{Definitions}

Patients with Aeromonas NF of limbs were enrolled in the study using the following criteria: (1) NF was defined either through histopathologic or surgical findings, such as the presence necrosis of the skin, subcutaneous fat, superficial fascia, or underlying muscles; (2) Aeromonas spp. was detected via isolation from soft tissue lesions and/or blood collected immediately after a patient's arrival at the ED or during surgery; and (3) these bacteria infected any limb $\mathrm{b}^{3,6,17,22}$.

Monomicrobial infection was documented by isolating single pathogenic bacteria as described above in criteria $(2)^{6,17}$. Polymicrobial infections were documented in patients from whom Aeromonas isolates in addition to other bacterial pathogens were isolated from soft tissue lesions and/or blood samples. Ineffective empirical antimicrobial usage was defined as the administration of antimicrobial regimens that may be ineffective against Aeromonas isolates according to antimicrobial susceptibility testing when patients arrived $\mathrm{ED}^{11,23}$.

Microbiology laboratory procedures. Gram-negative isolates that tested positive for cytochrome oxidase, glucose fermentation, citrate usage, indole production, and ornithine decarboxylase were classified as Aeromonas species. All strains were identified to the species level by conventional methods and were further verified by the API-20E and ID 32 GN Systems (bioMérieux Inc., Hazelwood, MO, USA), or the Vitek 2 ID-GNB identification card (bioMérieux Inc., Durham, NC, USA). These antimicrobial susceptibility tests were performed as recommended by the Clinical and Laboratory Standards Institute (CLSI), and the results were interpreted according to the CLSI criteria for these microorganisms.

Demographic data, clinical presentations, and laboratory findings. Patients with Aeromonas NF of limbs were categorized within survival and non-survival groups. Data such as demographics, comorbidities, presenting signs and symptoms, laboratory findings, microbiologic results, initial antibiotics usage, and treatment outcomes were recorded and compared.

Accordance. All procedures performed in studies involving human participants were in accordance with the ethical standards of the institutional and national research committee and with the 1964 Helsinki declaration and its later amendments or comparable ethical standards.

Informed consent. All participants provided their written informed consent following the protocols approved by the Institutional Review Board of Chang Gung Medical Foundation. In accordance to the ethical approval, consents were not required from deceased patients' relatives.

Statistical analysis. The predictors for mortality were determined using a multivariate logistic regression model. Categorical variables were tested by Fisher's exact test, continuous variables were tested by Student's $t$-test or the Mann-Whitney $U$ test, and a two-tailed $p$-value of $<0.05$ was considered statistically significant. Odds ratios (ORs) and 95\% confidence intervals (CIs) were calculated to evaluate the strength of any association, as well as the precision of the estimated effect. All statistical calculations were performed using the Statistical Package for the Social Sciences for Windows, version 18.0 (Chicago, IL, USA).

Ethics approval and consent to participate. This study protocol was approved by the Institutional Review Board of Chang Gung Medical Foundation (Number: 201801530B1B0).

\section{Data availability}

All datasets are available from the first author on reasonable request.

Received: 30 January 2020; Accepted: 21 April 2020;

Published online: 07 May 2020 


\section{References}

1. Wilsonm, B. Necrotizing fasciitis. Am. Surg. 18, 416-31 (1952).

2. Green, R. J., Dafoe, D. C. \& Raffin, T. A. Necrotizing fasciitis. Chest 110, 219-29 (1996).

3. Wong, C. H. et al. Necrotizing fasciitis: clinical presentation, microbiology, and determinants of mortality. J. Bone Jt. Surg. Am. 85, 1454-60 (2003)

4. Ward, R. G. \& Walsh, M. S. Necrotizing fasciitis: 10 years' experience in a district general hospital. Br. J. Surg. 78, 488-9 (1991).

5. Liu, J. W. et al. Prognostic factors and antibiotics in Vibrio vulnificus septicemia. Arch. Intern. Med. 166, 2117-23 (2006).

6. Lee, C. Y. et al. Prognostic factors and monomicrobial necrotizing fasciitis: gram-positive versus gram-negative pathogens. $B M C$ Infect. Dis. 11, 5 (2011).

7. Huang, K. F. et al. Independent predictors of mortality for necrotizing fasciitis: A retrospective analysis in a single institution. J. Trauma. 71, 467-73 (2011).

8. Tsai, Y. H. et al. Microbiology and surgical indicators of necrotizing fasciitis in a tertiary hospital of southwest Taiwan. Int. J. Infect. Dis. 16, e159-65 (2012).

9. Tsai, Y. H. et al. Necrotizing soft-tissue infections and sepsis caused by Vibrio vulnificus compared with those caused by Aeromonas species. J. Bone Jt. Surg. Am. 89, 631-6 (2007).

10. Lee, C. C. et al. Necrotizing fasciitis in patients with liver cirrhosis: Predominance of monomicrobial Gram-negative bacillary infections. Diagn. Microbiol. Infect. Dis. 62, 219-25 (2008).

11. Huang, T. Y. et al. Implementation and outcomes of hospital-wide computerized antimicrobial approval system and on-the-spot education in a traumatic intensive care unit in Taiwan. J. Microbiol. Immunol. Infect. 51, 672-80 (2018).

12. Tsai, Y. H. et al. Systemic Vibrio infection presenting as necrotizing fasciitis and sepsis. A series of thirteen cases. J. Bone Jt. Surg. Am. 86, 2497-502 (2004).

13. Tsai, Y. H., Hsu, R. W. W., Huang, K. C. \& Huang, T. J. Comparison of necrotizing fasciitis and sepsis caused by Vibrio vulnificus and Staphylococcus aureus. J. Bone Jt. Surg. Am. 93, 274-84 (2011).

14. Tsai, Y. H. et al. Monomicrobial Necrotizing Fasciitis Caused by Aeromonas hydrophila and Klebsiella pneumoniae. Med. Princ. Pract. 24, 416-23 (2015).

15. Tsai, Y. H. et al. Laboratory indicators for early detection and surgical treatment of Vibrio necrotizing fasciitis. Clin. Orthop. Relat. Res. 468, 2230-7 (2010).

16. Huang, K. C. \& Hsu, R. W. Vibrio fluvialis hemorrhagic cellulitis and cerebritis. Clin. Infect. Dis. 40, 75-7 (2005).

17. Huang, K. C. et al. Vibrio necrotizing soft-tissue infection of the upper extremity: factors predictive of amputation and death. J. Infect. 57, 290-7 (2008).

18. Chen, W. D. et al. Vibrio cholerae non-O1 - the first reported case of keratitis in a healthy patient. BMC Infect. Dis. 19, 916 (2019).

19. Chen, I. C. et al. The microbiological profile and presence of bloodstream infection influence mortality rates in necrotizing fasciitis. Crit. Care 15, R152 (2011).

20. Liu, Y. M. et al. Microbiology and factors affecting mortality in necrotizing fasciitis. J. Microbiol. Immunol. Infect. 38, 430-5 (2005).

21. Wang, J. M. \& Lim, H. K. Necrotizing fasciitis: eight-year experience and literature review. Braz. J. Infect. Dis. 18, 137-43 (2014).

22. Tsai, Y. H. et al. A multiplex PCR assay for detection of Vibrio vulnificus, Aeromonas hydrophila, methicillin-resistant Staphylococcus aureus, Streptococcus pyogenes, and Streptococcus agalactiae from the isolates of patients with necrotizing fasciitis. Int. J. Infect. Dis. 81, 73-80 (2019).

23. Kunin, C. M., Tupasi, T. \& Craig, W. A. Use of antibiotics. A brief exposition of the problem and some tentative solutions. Ann. Intern. Med. 79, 555-60 (1973).

24. Janda, J. M. \& Abbott, S. L. The genus Aeromonas: taxonomy, pathogenicity, and infection. Clin. Microbiol. Rev. 23, 35-73 (2010).

25. Gold, W. L. \& Salit, I. E. Aeromonas hydrophila infections of skin and soft tissue: report of 11 cases and review. Clin. Infect. Dis. 16, 69-74 (1993).

26. Ko, W. C. \& Chuang, Y. C. Aeromonas bacteremia: Review of 59 episodes. Clin. Infect. Dis. 20, 1298-304 (1995).

27. Chao, C. M. et al. Skin and soft-tissue infections caused by Aeromonas species. Eur. J. Clin. Microbiol. Infect. Dis. 32, 543-7 (2013).

28. Lamy, B., Kodjo, A. \& Laurent, F. Prospective nationwide study of Aeromonas infections in France. J. Clin. Microbiol. 47, 1234-7 (2009).

29. Janda, J. M. et al. Aeromonas species in septicemia: Laboratory characteristics and clinical observations. Clin. Infect. Dis. 19, 77-83 (1994).

30. Simon, T. P., Rajakulendran, S. \& Yeung, H. T. Acute hepatic failure precipitated in a patient with subclinical liver disease by vibrionic and clostridial septicemia. Pathology 20, 188-90 (1998).

31. Anaya, D.A. et al. Predictors of mortality and limb loss in necrotizing soft tissue infections. Arch Surg 140, 151-7; discussion 8 (2005).

32. Ko, W. C. et al. Clinical features and therapeutic implications of 104 episodes of monomicrobial Aeromonas bacteraemia. J. Infect. 40, 267-73 (2000).

33. Vila, J. et al. In vitro antimicrobial susceptibility of clinical isolates of Aeromonas caviae, Aeromonas hydrophila and Aeromonas veronii biotype sobria. J. Antimicrob. Chemother. 49, 701-2 (2002).

34. Aravena-Roman, M. et al. Antimicrobial susceptibilities of Aeromonas strains isolated from clinical and environmental sources to 26 antimicrobial agents. Antimicrob. Agents Chemother. 56, 1110-2 (2012).

35. Wong, C. H. \& Wang, Y. S. The diagnosis of necrotizing fasciitis. Curr. Opin. Infect. Dis. 18, 101-6 (2005).

36. McHenry, C. R. et al. Determinants of mortality for necrotizing soft-tissue infections. Ann. Surg. 221, 558-63 (1995).

37. Chuang, Y. C. et al. Vibrio vulnificus infection in Taiwan: report of 28 cases and review of clinical manifestations and treatment. Clin. Infect. Dis. 15, 271-276 (1996).

\section{Acknowledgements}

The authors wish to thank Miss Hsing-Jung Li for assistance in English modification. This work was supported by the Chang Gung Medical Research Program Foundation [grant numbers CMRPG6H0641].

\section{Author contributions}

Conceptualization, T.Y.H. and K.T.P.; Investigation and Methodology, T.Y.H. and W.H.H.; Formal analysis, T.Y.H. and C.H.H.; Writing-original draft preparation, T.Y.H. and F.Y.C.; Writing-review and editing, T.Y.H. and Y.H.T. All authors read and approved the final manuscript.

\section{Competing interests}

The authors declare no competing interests.

\section{Additional information}

Correspondence and requests for materials should be addressed to Y.-H.T. 
Reprints and permissions information is available at www.nature.com/reprints.

Publisher's note Springer Nature remains neutral with regard to jurisdictional claims in published maps and institutional affiliations.

(c) (i) Open Access This article is licensed under a Creative Commons Attribution 4.0 International License, which permits use, sharing, adaptation, distribution and reproduction in any medium or format, as long as you give appropriate credit to the original author(s) and the source, provide a link to the Creative Commons license, and indicate if changes were made. The images or other third party material in this article are included in the article's Creative Commons license, unless indicated otherwise in a credit line to the material. If material is not included in the article's Creative Commons license and your intended use is not permitted by statutory regulation or exceeds the permitted use, you will need to obtain permission directly from the copyright holder. To view a copy of this license, visit http://creativecommons.org/licenses/by/4.0/.

(C) The Author(s) 2020 